\title{
Detection of novel chromosome-SCCmec variants in Methicillin Resistant Staphylococcus aureus and their inclusion in PCR based screening
}

\author{
Anneke van der Zee ${ }^{1 *}$, Lieuwe Roorda ${ }^{1}$, Willem DH Hendriks ${ }^{1}$, Jacobus M Ossewaarde ${ }^{1,2}$ and \\ Johannes Buitenwerf ${ }^{1}$
}

\begin{abstract}
Findings: To facilitate automation, a novel DNA extraction method for MRSA was adopted. The MRSA specific chromosome-SCCmec PCR was adapted, additional primers were added, and the performance was validated. From various laboratories in The Netherlands we received a total of 86 MRSA clinical isolates, that were negative in commercially available tests. We identified 14 MRSA strains with new variant chromosome-SCCmec junctions by sequence analysis. These MRSA strains appeared to carry SCCmec sequences with a high degree of homology to SCC regions of S. epidermidis and S. haemolyticus. All were included for detection in chromosome-SCCmec based PCR.
\end{abstract}

Background: Efficient management of Methicillin Resistant Staphylococcus aureus (MRSA) in the hospital is needed to prevent dissemination. It is important that MRSA can be rapidly identified, and effective infection control measures can be initiated. Equally important is a rapid MRSA negative report, especially for patients in isolation. For negative screening we implemented fully automated high through-put molecular screening for MRSA.

Conclusions: Fourteen variant chromosome-SCCmec junctions in MRSA, that are not detected in commercially available MRSA detection kits were added to our PCR to detect all currently known variant SCC-mec types of MRSA.

\section{Background}

The dissemination of Methicillin Resistant Staphylococcus aureus (MRSA) in hospitals is a growing problem worldwide. In The Netherlands, a search and destroy policy is implemented [1]. Patients colonized with MRSA are kept in isolation until they are culture negative. A MRSA negative report can faster be obtained by PCR. Therefore, a molecular approach for negative screening of MRSA was exploited. Molecular detection of the mecA gene, which confers resistance to all $\beta$-lactams, has often been used in combination with other $S$. aureus specific genes in a multiplex PCR. Genes that are specific for $S$. aureus comprise for example of the sequence published by Martineau et al. [2], the nuclease gene $(n u c)$ [3,4], or the coagulase gene (coa) [5]. When clinical samples contain a mixture of coagulase negative staphylococci (CNS), methicillin sensitive

\footnotetext{
* Correspondence: zeea@maasstadziekenhuis.nl

'Maasstad Laboratory, Molecular Diagnostics Unit, Maasstad Hospital,

Olympiaweg 350, 3870HT Rotterdam, The Netherlands

Full list of author information is available at the end of the article
}

S. aureus (MSSA), and MRSA, a positive mecA PCR can be generated by CNS while both MSSA and MRSA generate a positive PCR for the coa or the nuc gene. Only culturing could confirm MRSA. Another approach for detection of MRSA was presented by a multiplex PCR described by Huletsky et al. [6]. This PCR specifically targets the junction between a conserved open reading frame orf $X$ in $S$. aureus, and the staphylococcal cassette chromosome containing the mecA gene (SCCmec). For MRSA, 8 different types of SCCmec elements have been classified [7]. The SCC is known to be a mobile heterogeneous genetic element that integrates site specifically into orf X. SCCmec is an SCC containing the mecA gene. SCC can also be present in CNS, not containing mecA but integrated into the analogous chromosomal location. MSSA can contain non-mecA-SCC or SCCmec elements which have lost the region containing $m e c A$. Several commercially available molecular screening tests are based on PCR amplification of the chromosome-SCCmec junction.

\section{Biomed Central}


In this study, a novel DNA extraction method for MRSA was adopted that virtually prevents PCR inhibition. The detection process was fully automated for high through-put of clinical materials. An extra 17 forward primers were added to PCR to detect several newly identified MRSA strains in this study carrying SCCmec variants and found to be present in The Netherlands, and possibly elsewhere. An adaptable PCR format is needed for reliable detection of all MRSA.

\section{Findings}

\section{Implementation and evaluation of orfX/SCCmec PCR}

The PCR as described by Huletsky et al. [6], was slightly adapted (Table 1).

To allow PCR detection of more MRSA types, a literature search was conducted. Forward primer F7 was derived from the sequence of $S$. aureus strain JCSC 3624 (WIS), accession number AB121219 [8], and was included in the PCR. Primer F10 was designed based on the sequence of S. aureus U10927 [9] (Table 1).
With the expanded orfX/SCCmec PCR a total of 1906 samples was investigated with high through-put screening; 303 were PCR positive, no inhibition of PCR was found. To verify whether a positive signal was due to viable or dead MRSA, all were cultured; 141 were culture positive, and $22 \%$ of 141 were found to be MSSA. The latter may have lost $m e c A$ regions or contain non-mecA SCC elements. All culture positive MRSA were confirmed by mecA/coa PCR. Thus, PCR is highly non specific. However, since all suspect samples are subsequently cultured, this is acceptable. With negative screening it is important that the negative predictive value is $100 \%$.

One MRSA isolate found by routine culture was negative in PCR. We analyzed the sequence of this strain (303480, Table 2) by genomic DNA sequencing with primer R1. A sequence of $345 \mathrm{bp}$ was obtained which was aligned to Genbank/EMBL DNA sequences using BLAST. No significant sequence homology was found except that the 35 bp flanking orfX showed 97\%

Table 1 Primer and probe sequences used in OrfX-SCC PCR

\begin{tabular}{|c|c|c|}
\hline primer/probe & Sequence $5^{\prime}-3^{\prime}$ & Reference \\
\hline$\overline{F 1}$ & GTCAAAAATCATGAACCTCATTACTTATG & according to Huletsky et al. \\
\hline$\overline{F 2}$ & AATATTTCATATATGTAATTCCTCCACATCTC & adapted from Huletsky et al. \\
\hline F3 & CTTCAAATATTATCTCGTAATTTACCTTGTTC & adapted from Huletsky et al. \\
\hline F4 & CTCTGCTTTATATTATAAAATTACGGCTG & according to Huletsky et al. \\
\hline$\overline{F 5}$ & TCACTITITATTCTTCAAAGATTTGAGC & adapted from Huletsky et al. \\
\hline$\overline{F 7}$ & CСATTCTTCCAAAAAATATATTTACTTTAGTC & This study \\
\hline$\overline{F 8}$ & TTTCATAATATGTGCTACGCAACCTA & This study \\
\hline$\overline{F 9}$ & CGAGTTAATTTTTATTTTAGAGCGCTTAC & This study \\
\hline F10 & CCGCTCCTITIATATTATACACAACCTATT & This study \\
\hline F11 & GCCATATTAATGCCTCACGAAAC & This study \\
\hline$\overline{F 12}$ & CATTCATTAACATCGTACTCTGCATTT & This study \\
\hline F13 & TCCCTITATGAAGCGGCTGAA & This study \\
\hline$\overline{F 14}$ & AAGCTATAGTTCAGCATTATCGTAAGTTAACT & This study \\
\hline F15 & TGCCAATCACAGTTCAATCAATTATT & This study \\
\hline$\overline{F 16}$ & TCCTTTCTAATTATATTATGCGCAACCT & This study \\
\hline$\overline{F 17}$ & ACTCTGATAAGCCATTCATTCATCCA & This study \\
\hline$\overline{F 18}$ & ACAATCCTAACATAAGATTGTGGCTTT & This study \\
\hline F20 & GCATATTCACTTTGATAAGCCATTCAT & This study \\
\hline$\overline{F 21}$ & CGGTTCTGATATCTTTTCAACCATT & This study \\
\hline$\overline{F 23}$ & CCCCTCCCATTAACTCCGTATAT & This study \\
\hline F24 & СССAAACTCTTAACTTСТTCAATACATT & This study \\
\hline F25 & TTCTAAGGTAGCTTCCCTITCAATAATTT & This study \\
\hline$\overline{\mathrm{R} 1}$ & CGTCATTGGCGGATCAAAC & adapted from Huletsky et al. \\
\hline$\overline{\mathrm{R} 2}$ & CGTCATTGGTGGATCAAACG & adapted from Huletsky et al. \\
\hline probe2 & FAM-CACAAGGATGTCTTACAACG-MGB & adapted from Huletsky et al. \\
\hline probe3 & FAM-CACAAGGACGTCTTACAACG-MGB & adapted from Huletsky et al. \\
\hline probe4 & FAM-CACAAAGACGTCTTACAACG-MGB & adapted from Huletsky et al. \\
\hline
\end{tabular}


Table 2 Observed sequence homologies of analyzed MRSA strains from various locations, length of DNA sequence analysis reads, and PCR primers based on these sequences

\begin{tabular}{|c|c|c|c|c|}
\hline Strain & Location & bp & Homology (\%) with accession number (species) corresponding to bp & primer \\
\hline $02 \mathrm{M} 023064$ & Breda & 222 & 94\% U10927 (S. aureus);bp 648-426 & F9 \\
\hline $\mathrm{JBZ12}$ & Den Bosch & 235 & 93\% AB539727 (S. aureus);bp 84645-84507 & F13 \\
\hline 261207168 & Enschede & 834 & 91\% AB063172 (S. aureus); bp 169-879 & F15 \\
\hline $\mathrm{JBZ33}$ & Den Bosch & 396 & 99\% EU272080 (S. aureus);bp 794-399 & $\mathrm{F} 23$ \\
\hline S0121 & Utrecht & 280 & 100\% EU263618 (S. aureus);bp 655-376 & $\mathrm{F} 17$ \\
\hline $\mathrm{CC} 8$ & Denmark ( ) & 422 & 99\% BK001539 (S. epidermidis);bp 19437-19016 & $\mathrm{F} 20$ \\
\hline 434-1819 & Eindhoven & 416 & 99\% BK001539 (S. epidermidis);bp 34917-34205 & F24 \\
\hline S0089 & Utrecht & 409 & 100\% AP006716 (S. haemolyticus);bp 52718-52358 & F16 \\
\hline 582 & Utrecht & 344 & 98\% AP006716 (S. haemolyticus);bp 91374-91031 & F18 \\
\hline 060120 & Leiden & 912 & 98\% AP006716 (S. haemolyticus);bp 30663-29755 & $\mathrm{F} 25$ \\
\hline 303480 & Rotterdam & 345 & CGCAACCTATTTITAATTTTATTTGTGATAtGCT & F8 \\
\hline 251110219 & Enschede & 900 & CAACtTATTITTAGTTTTATTTGTGATACGCTTCT & F14 \\
\hline JBZ54 & Den Bosch & 688 & No significant homology found & $F 21$ \\
\hline 40295861 & Breda & 417 & No significant homology found & F11 \\
\hline 40461611 & Breda & 762 & No significant homology found & $\mathrm{F} 12$ \\
\hline
\end{tabular}

homology with a repeated sequence found in S. haemolyticus (AP006716;bp 52313, and 91034), also present in $S$. saprophyticus (AP08934;bp 50105). A new primer in PCR (primer F8, Table 1) was derived from the obtained sequence. To minimize the chance for more false-negative PCR results for MRSA, other laboratories in The Netherlands were asked for MRSA strains that were negative in commercial molecular tests used by these laboratories. We received a total of 86 clinical isolates or DNA. Whenever a strain was also negative in our orf X/SCCmec PCR, DNA was sequenced and a new primer was added to PCR. Of 86 strains, another 14 additional forward primers were designed, apart from 2 literature based primers, and 1 primer based on a MRSA strain from our own hospital. All 17 primers were included in PCR to a total of 22 forward primers (Table 1).

\section{Sequence analysis of PCR negative MRSA strains}

All 14 strains mentioned above were verified to be MRSA using mecA/coa PCR. All were positive in both PCRs. The results of DNA sequence analysis are presented in Table 2. BLAST comparisons were made with the sequences cut off at the $\operatorname{orf} X$ according to Ito et al. [10]. Within the $\operatorname{orf} X$ gene, the obtained sequences were highly homologous and consistently aligned to $S$. aureus orf X.

The SCCmec of 5 strains showed various degrees of homology (91-100\%) with different parts of SCCmec sequences of $S$. aureus strains. Two MRSA strains showed 99\% homology with S. epidermidis SCC, but with different regions. Another 3 strains were homologous to $S$. haemolyticus in their orf $X$ flanking sequences. BLAST alignments of strains 303480 and 251110219 showed no significant sequence homologies except for a 35 bp repeat (CAACtTATTTTTTAGTTTTATTTGTGATACGCTTCT)found present in S. haemolyticus and S. saprophyticus. The orf $X$ flanking regions of 3 other strains showed no significant homology to any Genbank/EMBL sequences.

\section{Comparison of right SSCmec-OrfX junctions}

The alignment of right SCCmec-OrfX junctions is shown in Figure 1. The direct repeat consensus (-A-TTTGATA-GC-TC, [10]) is largely intact, suggesting that SCC sequences from S. epidermidis and S. haemolyticus were acquired by recombination rather than by transposition.

\section{Discussion}

The staphylococcal cassette chromosome SCCmec is a genetic mobile element that contains the methicillin resistant $m e c A$ gene [8]. Its site-specific insertion or excision is mediated by cassette chromosome recombinase (ccr) complex and by the presence of direct and inverted repeats at the SCCmec extremities. The combination of classes of mec gene complex and $c c r$ gene complex forms the basis of their classification [10]. At present 8 types of SCCmec elements have been classified $[7,11]$. In addition, SCCmec can harbour other drug resistant genes, and insertion sequence elements (IS431, IS1272), transposons (Tn4001, Tn554) or plasmids (pUB110, pT181). The chromosome flanking regions (junction or J-regions, formerly, junkyard regions) of SCCmec are most variable in their DNA sequences. 


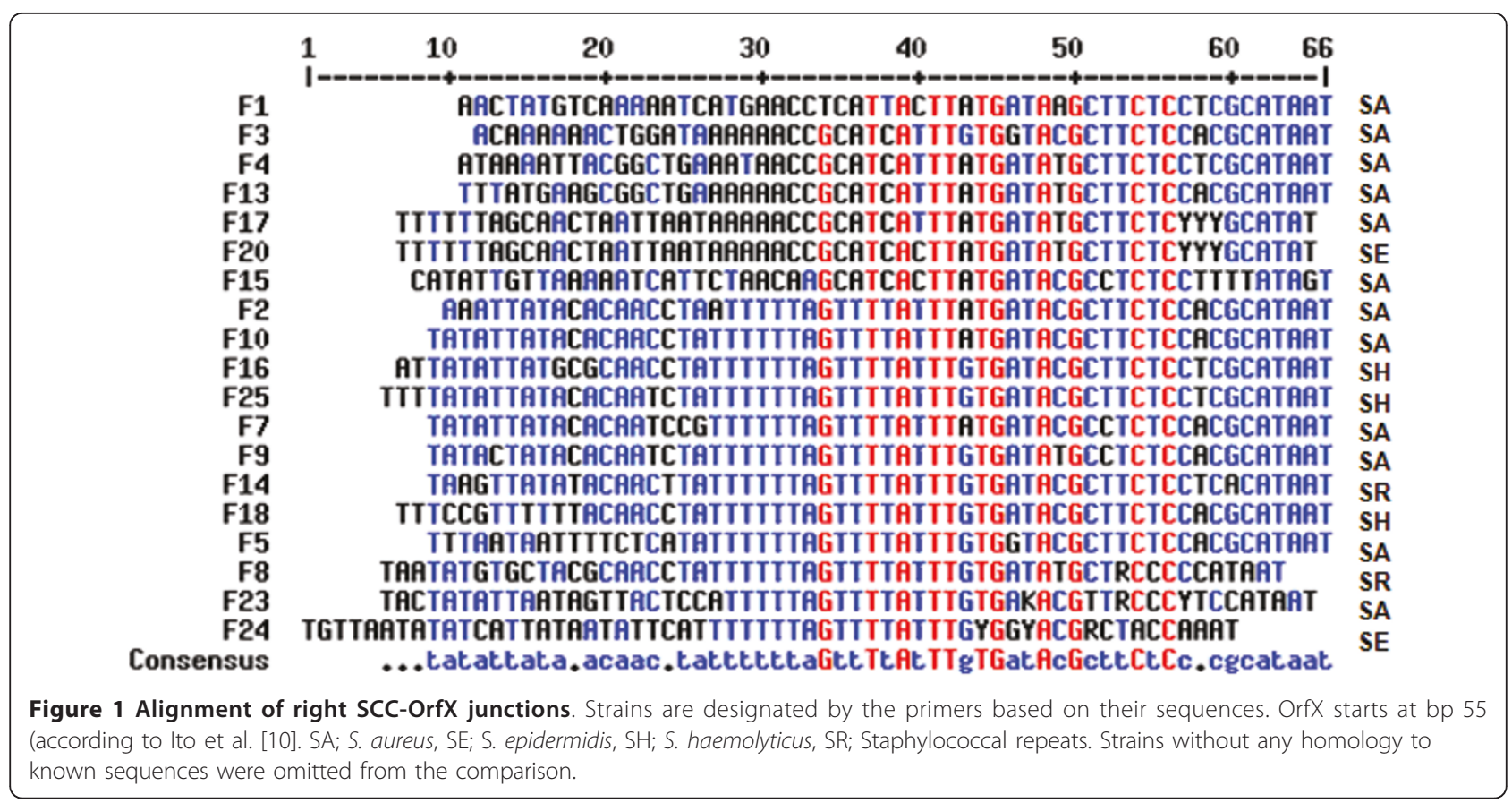

We adapted the PCR described by Huletsky et al. [6], based on amplification of the chromosome-SCCmec junction. We initially included 2 more forward primers to expand detection to MRSA known from literature. After sequence analysis of 14 MRSA strains that were not recognized by the initial primer set, we included additional primers resulting in a megaplex PCR with 14 primers based on sequences of newly identified MRSA with variant $\mathrm{SCCmec}$ sequences to a total of 21 forward primers. No adverse effects on PCR were seen with this number of primers.

From 3 strains the sequenced SCCmec region did not match any known DNA sequence, presuming a nonhuman relation. In The Netherlands live-stock associated MRSA is increasingly isolated [12]. Reischl et al. [13] have shown that live-stock associated MRSA can be discriminated on the basis of a $\mathrm{G} \rightarrow \mathrm{A}$ mutation in $\operatorname{orf} X$. Based on the finding that these strains were only positive in PCR when the probe harbouring this mutation (probe 2) was used, we confirmed that these 3 strains were most probably live-stock associated MRSA.

In the SCCmec of the other new strains, repeated sequences as IS431 and IS1272 were found. IS elements are mobile and can move by transposition. The similar but not identical repeats found in strain 303480 and 251110219, might be related to an IS1272 encoded truncated transposase as was indicated by BLAST homology. This suggested that the variant SCCmec sequences resulted from transposition. Therefore the right chromosome-SCCmec junctions carried by the new MRSA strains were compared. The consensus represented the direct repeat (DR) involved in insertion and excision of $\mathrm{SCC} m e c$. Consequently, the variant SCCmec sequences were acquired by recombination rather than transposition. Mongkolrattanothai et al. [14], reported a nonmecA-SCC element present in S. epidermidis with $3 \mathrm{DR}$ highly homologous to $S$. aureus, 2 at the extremities of the element and 1 in the middle. The 2 MRSA strains carrying different SCC homologs of S. epidermidis in this study, were each highly homologous to the SCC described by Mongkolrattanothai [14], but represented the sequence on either side of the middle DR. This finding may corroborate the recombination theory, regardless of the orientation of the inserted SCC in the 2 MRSA strains. Whether $m e c A$ is carried on the acquired SCC from S. epidermidis of the MRSA strains found in our study, as well as SCC typing, remains a topic for future studies.

In conclusion, it appears that MSSA can convert to MRSA by acceptance of SCC sequences from CNS. This process may be driven by selection pressure of antibiotics. Indeed, an isogenic pair of MSSA and MRSA was recently described that supports the occurrence of horizontal transfer of SCCmec between Staphylococcal species [15]. The 86 strains not detected as being MRSA in other laboratories by commercially available tests raises concern about their performance [16,17]. Exploiting the SCCmec junction as target in PCR used for detection of MRSA requires continuous awareness of possible variants. PCR based on mecA/nuc gene does 
not seem to present an acceptable alternative because the nuc gene may be absent as has been found earlier [18]. The mecA/coa PCR, combined with chromosomeSCCmec junction PCR identifies other MRSA variants that may arise.

\section{Conclusions}

We identified 14 new variant chromosome-SCCmec junctions in MRSA, that are not detected in commercially available MRSA detection kits. We adapted our PCR to detect all known variant chromosome-SCC-mec types of MRSA.

Fully automated high through-put detection and robust DNA extraction support an adaptable PCR format for detection of these newly identified MRSA strains. Moreover, this system can easily be expanded with novel PCR primers when new variants of chromosome-SCCmec types in MRSA may arise.

\section{Methods}

\section{Clinical samples}

Samples were taken from nose, throat, and perineum, and if appropriate also from wounds, sputum, and catheters (Transwab, Medical Wire \& Equipment Co. Ltd., Corsham, Wilts., England) in the context of patient and personnel screening as required by the Dutch policy for MRSA control. Since no extra action or sampling was requested than the medically indicated, informed consent was not asked and no ethical approval was required, in conformity to the guidelines of the Dutch Central Committee on Research involving Human Subjects. Swabs were inoculated into $5 \mathrm{ml}$ phenyl mannitol broth (PHMB) containing ceftizoxime and aztreonam [19] for overnight incubation. After at least 18 hours of incubation, PHMB broth was subjected to PCR.

\section{Automated DNA isolation, PCR detection, and data output by MRSA-screen with PCR amplification of OrfX-SCCmec junction}

PHMB tubes were placed into the MultiPROBE II PLUS HT Expanded pipetting robot (PerkinElmer Life and Analytical Sciences). This system is equipped with a bar-code reader and automated plate sealer (RoboSeal). This system handles the DNA extraction, PCR assay setup, and sealing of the plate. Next, the plates are automatically transferred to a real-time ABI 7900HT thermocycler (Applied Biosystems, Nieuwerkerk a/d IJssel, The Netherlands). Thus, barcode scanning, DNA extraction, pipetting, sealing of the 384-well PCR Plate, creating a run file and starting the PCR, were done by the system without interference or need of presence of a technician. Results were automatically transferred to the Laboratory Information System.
Software was programmed by PerkinElmer to perform the following steps. After barcode reading, $5 \mathrm{ml}$ of saline was added and mixed by pipetting. This $1: 1$ dilution served to elevate the fluid level and to prevent the 9.5 $\mathrm{cm}$ long probes touching the swabs in the $15 \mathrm{~cm}$ long tubes.

Template DNA was prepared by using the Extract-NAmp ${ }^{\text {TM }}$ Plant PCR Kit (SIGMA, Munich, Germany). In short, $50 \mu$ l sample was mixed with $100 \mu$ SIGMA Extraction Solution (E7526). The mixture was incubated at $95{ }^{\circ} \mathrm{C}$ for 10 minutes, cooled to room temperature, $100 \mu$ l SIGMA Dilution Buffer (D5688) was added and mixed. This DNA sample is PCR ready when used in combination with the SIGMA Extract-N-Amp PCR ReadyMix ${ }^{\mathrm{TM}}$ (E3004).

Primers and probes for detection of the OrfX-SCCmec junction were used in one primer-probe mixture with the following concentrations; $600 \mathrm{nM}$ for each $\mathrm{F}$ and $\mathrm{R}$ primer, and $120 \mathrm{nM}$ for each probe (Table 1). Each sample was tested with this primer-probe mixture. Amplification reactions were performed in a volume of $20 \mu \mathrm{l}$, with $10 \mu \mathrm{l}$ SIGMA Extract-N-Amp PCR Reaction Mix $^{\mathrm{TM}}$ (including 4\% Reference Dye) in $6 \mu \mathrm{l}$ primerprobe mix and $4 \mu \mathrm{l}$ of the DNA sample. Amplification consisted of $3 \mathrm{~min}$ at $95{ }^{\circ} \mathrm{C}$ followed by 44 cycles of 15 $\mathrm{s}$ at $95{ }^{\circ} \mathrm{C}$ and $60 \mathrm{~s}$ at $60^{\circ} \mathrm{C}$. In each run a MRSA positive and a negative control was included. A sample was regarded suspect for MRSA in the MRSA-screen if the PCR was positive. Positive samples were subsequently cultured on blood agar plates.

\section{MecA/coa gene PCR}

The mecA PCR was carried out as described [4], with $800 \mathrm{nM}$ of each primer. PCR for coa was as described previously [5]. The concentration of primers Coag2: CGAGACCAAGATTCAACAAG, and Coag3: AAAGAAAACCACTCACATCA was $800 \mathrm{nM}$ each. MecA/coa PCR was used to confirm MRSA isolates. Results of $m e c A$ and coa PCR were analyzed using agarose gel electrophoresis.

\section{DNA sequence analysis}

Sequence analysis was performed by Baseclear, Leiden, The Netherlands on total chromosomal DNA with primer R1 (Table 1). Partial sequences of variant SCCmec have not yet been submitted but will be classified in further studies according to the recommendations of the International working group on the classification of staphylococcal cassette chromosome elements [11].

\section{Acknowledgements}

We gratefully acknowledge our colleagues who kindly provided their strains; Anneke Bergmans PhD., and Jan Kluytmans PhD., Amphia Hospital, Breda, Adriaan van den Brule PhD., Lab for Medical Microbiology, PAMM Regional 
Laboratory, Eindhoven/Veldhoven, The Netherlands, Eric Claas PhD. University Medical Center, Leiden, Ad Fluit PhD., and Adrienne Box BSc, University Medical Center Utrecht, Utrecht, Gerda Noordhoek PhD., Centre for Infectious Diseases Friesland, Leeuwarden, Ron Hendrix MD, PhD., Labmicta, Enschede, Mirjam Hermans PhD., Jeroen Bosch Hospital, Den Bosch, Ludo Oostendorp BSc, Laboratory for Infectious Diseases, Groningen, Dorthe Ørnskov, PhD, Sygehus Lillebælt, Vejle (Denmark), Thera Trienekens PhD., VieCuri Medisch Centrum voor Noord-Limburg, Venlo.

\section{Author details}

'Maasstad Laboratory, Molecular Diagnostics Unit, Maasstad Hospital, Olympiaweg 350, 3870HT Rotterdam, The Netherlands. 'Erasmus Medical Centre, Rotterdam, The Netherlands.

\section{Authors' contributions}

AZ drafted the manuscript and carried out the analysis of data. LR carried out the molecular genetic studies, and participated in the design of PCR. $\mathrm{WDHH}$ and $\mathrm{JB}$ conceived of the study and participated in its design. JMO helped to draft the manuscript. All authors read and approved the final manuscript.

\section{Competing interests}

The authors declare that they have no competing interests.

Received: 30 March 2011 Accepted: 26 May 2011

Published: 26 May 2011

\section{References}

1. Vos MC, Ott A, Verbrugh HA: Successful Search-and-Destroy Policy for Methicillin-Resistant Staphylococcus aureus in The Netherlands. J Clin Microbiol 2005, 43(4):2034-2035.

2. Martineau F, Picard FJ, Roy PH, Ouellette M, Bergeron MG: Species-specific and ubiquitous-DNA-based assays for rapid identification of Staphylococcus aureus. J Clin Microbiol 1998, 36:618-623.

3. Francois P, Bento M, Renzi G, Harbarth S, Pittet D, Schrenzel J: Evaluation of Three Molecular Assays for Rapid Identification of Methicillin-Resistant Staphylococcus aureus. J Clin Microbiol 2007, 45:2011-2013.

4. Geha D J, Uhl J R, Gustaferro C A, Persing D H: Multiplex PCR for identification of methicillin-resistant staphylococci in the clinical laboratory. J Clin Microbiol 1994, 32:1768-1772.

5. Goh S H, Byrne SK, Chow AW: Molecular typing of Staphylococcus aureus on the basis of coagulase gene polymorphisms. J Clin Microbiol 1992, 30:1642-1645.

6. Huletsky A, Giroux R, Rossbach V, Gagnon M, Vaillancourt M, Bernier M, Gagnon F, Truchon K, Bastien M, Picard FJ, van Belkum A, Ouellette M, Roy PH, Bergeron MG: New real-time PCR assay for rapid detection of methicillin resistant Staphylococcus aureus directly from specimens containing a mixture of staphylococci. J Clin Microbiol 2004, 42:1875-1884.

7. Chongtrakool $\mathrm{P}$, Ito $\mathrm{T}$, Ma XX, Kondo $\mathrm{Y}$, Trakulsomboon S, Tiensasitorn $\mathrm{C}$, Jamklang M, Chavalit T, Song JH, Hiramatsu K: Staphylococcal Cassette Chromosome mec (SCCmec) Typing of Methicillin-Resistant Staphylococcus aureus Strains Isolated in 11 Asian Countries: a Proposal for a New Nomenclature for SCCmec Elements. Antimicrob Agents Therap 2006, 50(3):1001-1012.

8. Ito T, Katayama Y, Asada K, Mori N, Tsutsumimoto K, Tiensasitorn C, Hiramatsu K: Structural comparison of three types of staphylococcal cassette chromosome mec integrated in the chromosome in methicillinresistant Staphylococcus aureus. Antimicrob Agents Therap 2001, 45:1323-1336.

9. Lin WS, Cunneen T, Lee CY: Sequence analysis and molecular characterization of genes required for the biosynthesis of type 1 capsular polysaccharide in Staphylococcus aureus. J Bacteriol 1994, 176(22):7005-7016.

10. Ito T, Ma XX, Takeuchi F, Okuma K, Yuzawa H, Hiramatsu K: Novel type V staphylococcal cassette chromosome mec driven by a novel cassette chromosome recombinase, ccrC. Antimicrob Agents Therap 2004, 48:2637-2651.

11. International working group on the classification of staphylococcal cassette chromosome elements (IWG-SCC): Classification of Staphyloccoccal Casette chromosome mec (SCCmec): Guidelines for reporting novel sCCmec elements. Antimicrob Agents Therap 2009, 53(12):4961-4967.
12. De Neeling AJ, van den Broek MJ, Spalburg EC, van Santen-Verheuvel MG, Dam-Deisz WDC, Boshuizen HC, van de Giessen AW, van Duijkeren E, Huijsdens XW: High prevalence of methicillin resistant Staphylococcus aureus in pigs. Vet Microbiol 2007, 122(3-4):366-72.

13. Reischl U, Frick J, Hoermansdorfer S, Melzl H, Bollwein M, Linde HJ, Becker K, Köck R, Tuschak C, Busch U, Sing A: Single-nucleotide polymorphism in the SCCmec-orfX junction distinguishes between livestock-associated MRSA CC398 and human epidemic MRSA strains. Euro Surveill 2009, 14(49):19436

14. Mongkolrattanothai K, Boyle S, Murphy TV, Daum RS: Novel non-mecAcontaining staphylococcal chromosomal cassette composite island containing pbp4 and tagF genes in a commensal staphylococcal species: A possible reservoir for antibiotic resistance islands in Staphylococcus aureus. Antimicrob Agents Therap 2004, 48:1823-1836.

15. Bloemendaal ALA, Brouwer EC, Fluit AC: Methicillin Resistance transfer from Staphylococcus epidermidis to Methicillin-susceptible Staphylococcus aureus in a patient during antibiotic therapy. PLOS ONE 2010, 5(7):e11841.

16. Bartels MD, Boye K, Rohde SM, Larsen AR, Torfs H, Bouchy P, Skov R, Westh $\mathrm{H}$ : A common variant of staphylococcal cassette chromosome mec type IVa in isolates from Copenhagen, Denmark, is not detected by the BD GeneOhm methicillin-resistant Staphylococcus aureus assay. J Clin Microbiol 2009, 47(5):1524-7.

17. Ornskov D, Kolmos B, Bendix Horn P, Nederby Nielsen J, Brandslund I, Schouenborg P: Screening for methicillin-resistant Staphylococcus aureus in clinical swabs using a high-throughput real-time PCR-based method. Clin Microbiol Infect 2008, 14:22-28.

18. van Leeuwen W, Roorda L, Hendriks W, Francois P, Schrenzel J: A nucdeficient meticillin-resistant Staphylococcus aureus strain. FEMS Immunol Med Microbiol 2008, 54:157.

19. Wertheim $H$, Verbrugh $H A$, van Pelt $C$, de Man $P$, van Belkum $A$, Vos MC: Improved detection of methicillin-resistant Staphylococcus aureus using phenyl mannitol broth containing aztreonam and ceftizoxime. J Clin Microbiol 2001, 39:2660-2662.

doi:10.1186/1756-0500-4-150

Cite this article as: van der Zee et al.: Detection of novel chromosomeSCCmec variants in Methicillin Resistant Staphylococcus aureus and their inclusion in PCR based screening. BMC Research Notes 2011 4:150.

\section{Submit your next manuscript to BioMed Central and take full advantage of:}

- Convenient online submission

- Thorough peer review

- No space constraints or color figure charges

- Immediate publication on acceptance

- Inclusion in PubMed, CAS, Scopus and Google Scholar

- Research which is freely available for redistribution

Submit your manuscript at www biomedcentral com/submit
C Biomed Central 